\title{
Evaluation of a commercial ELISA for ' serodiagnosis of Helicobacter pylori infection
}

\author{
J E Crabtree, T M Shallcross, R V Heatley, J I Wyatt
}

\begin{abstract}
A commercial ELISA for the detection of Helicobacter pylori IgG antibodies was evaluated using serum from 242 patients attending an endoscopy clinic. The efficacy of the ELISA was assessed in relation to the histological detection of $H$ pylori on antral mucosal biopsy specimens. In patients under 61 years of age $(n=138)$ the ELISA was $97 \cdot 5 \%$ sensitive and $85.5 \%$ specific for $H$ pylori infection, with a positive predictive value of $91 \%$ and a negative predictive value of $96 \%$. Over the whole group the sensitivity of the ELISA was $93.8 \%$ and the specificity $79 \cdot 3 \%$. The positive predictive value and negative predictive values were, respectively, $90 \%$ and $87 \%$. These results suggest that the Bio-Rad GAP IgG $H$ pylori ELISA is suitable for serodiagnosis of $\boldsymbol{H}$ pylori infections for most clinical purposes and thus makes $H$ pylori serology available to routine diagnostic laboratories.
\end{abstract}

Colonisation of the human gastric mucosa by Helicobacter pylori stimulates a specific systemic humoral response to the bacterium. ${ }^{1-7}$ Although early investigations showed the presence of a systemic immune response by agglutination and complement fixation techniques, ${ }^{67}$ more recent studies have shown the suitability of the enzyme linked immunosorbent assay (ELISA) for detection of $H$ pylori specific antibodies. ${ }^{1-58-11}$ Several different antigen preparations and methods have been used in these ELISAs and there has been no universal attempt to standardise assays. $H$ pylori serology has thus remained largely a research tool and not generally applicable to routine diagnostic laboratories. The increasing evidence implicating $H$ pylori in the aetiology of gastritis and perhaps also peptic ulcer disease ${ }^{12}$ makes accurate diagnosis of infection by non-invasive techniques such as ELISA clinically relevant.

In this study we evaluated the first commercially available $H$ pylori IgG ELISA. The efficacy of the assay was assessed in relation to the histological detection of the bacterium on the antral mucosa in a well defined group of patients.

\section{Methods}

Two hundred and forty two patients (104 men, 138 women; mean age $56 \cdot 7$, range $19-95$ ) undergoing routine upper gastrointestinal endoscopy were studied. Blood was taken immediately before endoscopy and sera were stored at $-20^{\circ} \mathrm{C}$ until assayed. At endoscopy, biopsy specimens were taken from the gastric antrum and body using large biopsy forceps (Olympus/Keymed ref FB 13K) and immediately fixed in $4 \%$ neutral buffered formalin for histological assessment.

Specimens were routinely processed and stained with haematoxylin and eosin. The presence and severity of gastritis was assessed by one pathologist (JIW) using Whitehead's classification. ${ }^{13}$ Chemical gastritis was assessed according to the criteria of Wyatt and Dixon. ${ }^{14}$ $H$ pylori were identified histologically with a modified Giemsa stain, ${ }^{15}$ and patients were considered positive if $H$ pylori was found in any biopsy specimen. It has been shown that there is the potential for sampling error when assessing $H$ pylori histologically. ${ }^{16}$ To avoid including false negative patients in the $H$ pylori negative group, those in whom chronic superficial or atrophic gastritis was present, but in whom $H$ pylori was not identified in any biopsy specimen, were excluded from the study. The patients selected should therefore represent "true positive" and "true negative" cases.

Serum IgG $H$ pylori antibodies were measured using a semiquantitative commercial IgG ELISA for $H$ pylori (Bio-Rad, GAP Test IgG) according to the manufacturer's instructions (the approximate cost per sample assayed in duplicate being $£ 4.06$ ). This ELISA utilises a DEAE-ion exchange chromatography purified $H$ pylori antigen preparation. Serial twofold dilutions ( 1 in 2 to 1 in 16) of positive (P) control sera and negative $(N)$ control sera were assayed in duplicate on each ELISA plate to determine the cut off point for semiquantitative analysis, based on a $P: N$ ratio. Semiquantitative titres $3+, 2+, 1+$, and $+1-$ were respectively assigned to the $P / N$ values derived from 1 in 2,1 in 4,1 in 8 , and 1 in 16 positive control dilutions. In determining the sensitivity and specificity of the assay patients with semiquantitative titres $3+, 2+$, and $1+$ were considered seropositive. Patients with semiquantitative titres $+/-$ or $\mathbf{P} / \mathrm{N}$ values below that of the 1 in 16 dilution of the positive control sera were considered seronegative. Intra-assay variability for IgG was $11 \%$ and interassay variability $12 \cdot 3 \%$.

Sera of patients who were serologically positive in $H$ pylori IgG ELISA but histologically negative for the bacterium were 
Table 1 Histology of antral mucosa in $H$ pylori positive and negative subjects

\begin{tabular}{lcc}
\hline & $\begin{array}{c}\text { H pylori } \\
\text { negative } \\
(n=82)\end{array}$ & $\begin{array}{l}\text { H pylori } \\
\text { positive } \\
(n=160)\end{array}$ \\
\hline Normal & 65 & 0 \\
Superficial gastritis & 0 & 43 \\
Chronic atrophic gastritis & 0 & 117 \\
Chemical gastritis & 16 & 0 \\
Fibrosis & 1 & 0 \\
\hline
\end{tabular}

further analysed for $H$ pylori IgG antibodies by immunoblotting. ${ }^{17}$ The antigen preparation was a whole cell preparation of $H$ pylori, strain NCTC 11637.

\section{Results}

One hundred and sixty of the 242 patients were colonised with $H$ pylori and 82 patients were negative for $H$ pylori. The histological diagnosis in the $H$ pylori positive and negative patients is shown in table 1 . None of the $H$ pylori positive subjects had histologically normal antral mucosa, 43 had superficial gastritis, and 117 had chronic atrophic gastritis. In eight patients $H$ pylori was identified only in biopsy specimens from the gastric body but not the antrum. All of these patients had superficial or chronic atrophic antral gastritis. In $H$ pylori negative patients the antral mucosa was histologically normal in $65 ; 16$ had chemical gastritis and one fibrosis.

Optical densities and semiquantitative titres in the $H$ pylori IgG ELISA for $H$ pylori positive and negative subjects are shown, respectively, in the figure and table 2 . Ten of the 160 histologically positive subjects were serologically negative $(+/-$ or negative). Conversely, 17 of the 82 histologically negative subjects were serologically positive with semiquantitative titres of $3+, 2+$, or $1+$. Three of the 17 seropositive patients had a histological picture of chemical gastritis; these three patients were also positive by immunoblotting for $H$ pylori IgG antibodies, while all 14 seropositive patients with normal histology were negative by immunoblotting (data not shown). The sensitivity of the ELISA is $93.8 \%$ and the specificity $79.3 \%$. The assay has a positive predictive value of $90 \%$ and a negative

Optical densities of $H$ pylori negative and positive patients in $H$ pylori IgG ELISA.

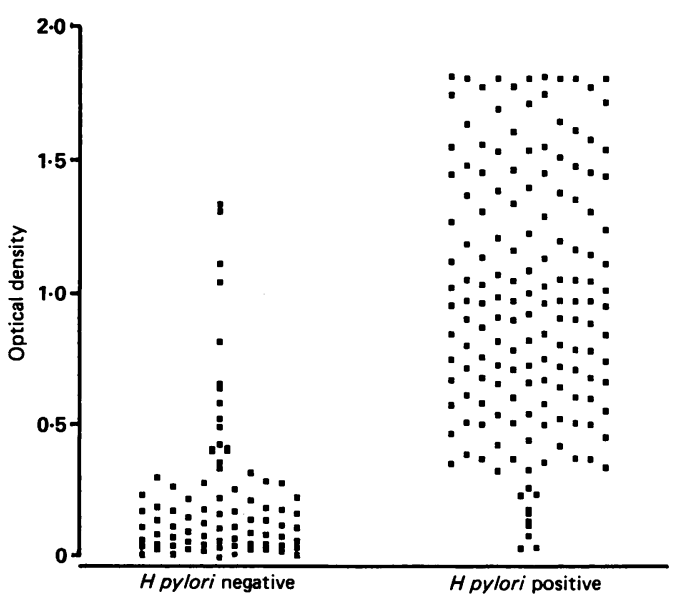

Table 2 Semiquantitative titre in H pylori IgG ELISA for $H$ pylori positive and negative subjects

\begin{tabular}{llc}
\hline Semiquantitative titre & $\begin{array}{l}\text { H pylori } \\
\text { positive } \\
(n=160)\end{array}$ & $\begin{array}{l}\text { H pylori } \\
\text { negative } \\
(n=82)\end{array}$ \\
\hline $3+$ & 100 & 5 \\
$2+$ & 35 & 5 \\
$1+$ & 15 & 7 \\
+- & 4 & 16 \\
Negative & 6 & 49 \\
\hline
\end{tabular}

predictive value of $87 \%$ (table 3). Exclusion of the three histologically negative patients who were positive by immunoblotting from analysis improves the assay specificity to $82 \cdot 3 \%$.

Our recent studies have shown that in the elderly the correlation between seropositivity and histological evidence of colonisation with $H$ pylori is poor. Because serology is a possible tool for screening younger dyspeptic patients, the results were also analysed to include only patients under 61 years of age $(n=138)$. The semiquantitative titres for these patients in the $H$ pylori ELISA are shown in table 4. Only two of the $H$ pylori positive patients were serologically negative and eight of the $H$ pylori negative subjects were serologically positive. For patients under 61 years of age, the sensitivity of the ELISA was $97.5 \%$ and the specificity $85.5 \%$, the positive predictive value $91 \%$ and the negative predictive value $96 \%$ (table 3).

\section{Discussion}

In this study we assessed a commercial $H$ pylori IgG ELISA with respect to histological evidence of $H$ pylori colonisation of the antral mucosa. Histological detection of $H$ pylori in gastric biopsy specimens compares well with other techniques, ${ }^{18}$ and in particular does not seem to give false positive results. It has the added advantage of permitting concurrent assessment of gastritis in biopsy specimens. In evaluating serological positivity against histological positivity, however, one must take account of the possibility of false negative histology resulting from patchy infection. Alternative validation procedures, such as bacterial culture or urease testing, would be subject to the same variability. ${ }^{18}$ Conversely, histologically positive patients with no systemic $H$ pylori IgG antibodies could be subjects in the early stages of infection. ${ }^{19}$

The sensitivity and specificity of any $H$ pylori IgG ELISA are strongly influenced by the chosen "cut off" point as well as the antigen preparation used. A high "cut-off" titre improves the specificity but reduces the sensitivity; conversely, a low titre "cut-off" increases the sensitivity but reduces the specificity. ${ }^{3}$

The sensitivity and specificity obtained with the commercial $H$ pylori IgG ELISA in this study compare favourably with the results of other non-commercial $H$ pylori ELISAs. The reported sensitivities and specificities for $H$ pylori IgG ELISAs vary according to the antigen preparation used. Sensitivity with an acid glycine extract of $H$ pylori ranged from 81- 
Table 3 Sensitivity, specificity, positive (PPV) and negative (NPV) predictive values for Bio-Rad IgG H pylori

\begin{tabular}{lllll}
\hline & Sensitivity & Specificity & PPV & NPV \\
\hline Age range 19-95 years $(\mathrm{n}=242)$ & $93.8 \%$ & $79 \cdot 3 \%$ & $90 \%$ & $87 \%$ \\
Under 61 years $(\mathrm{n}=138)$ & $97 \cdot 5 \%$ & $\mathbf{8 5} \cdot 5 \%$ & $91 \%$ & $96 \%$ \\
\hline
\end{tabular}

Table 4 Semiquantitative titre in $H$ pylori IgG ELISA for $H$ pylori positive and negative subjects under 61 years of age

\begin{tabular}{llc}
\hline Semiquantitative titre & $\begin{array}{l}\text { Hpylori } \\
\text { positive } \\
(\boldsymbol{n}=\$ 3)\end{array}$ & $\begin{array}{l}\text { H pylori } \\
\text { negative } \\
(\boldsymbol{n}=55)\end{array}$ \\
\hline $3+$ & 58 & 1 \\
$2+$ & 17 & 2 \\
$1+$ & 6 & 5 \\
$+/-$ & 0 & 12 \\
Negative & 2 & 35 \\
\hline
\end{tabular}

$99 \%$ and specificity from $78-97 \% .^{3}$ ELISAs using a crude urease preparation showed improved sensitivity $(100 \%)$ but reduced specificity $(79 \%){ }^{20}$ Sonicated whole cell $H$ pylori antigens have a specificity of $90 \%$ and a sensitivity of $96.5 \%$ when assessed against a small sample of culture positive patients with histological gastritis, assessment against histological gastritis alone giving a specificity of $92.9 \%$ and a sensitivity of $73.2 \% .{ }^{10}$ Recently $H$ pylori ELISAs based on high molecular weight cell-associated proteins have been described which are $98.7 \%$ sensitive and $100 \%$ specific. ${ }^{11}$ Inclusion of a 120 kilodalton $H$ pylori protein with ultracentrifuged sonicate antigen preparations or acid glycine extracts improved both sensitivity $(97 \%)$ and specificity $(100 \%){ }^{21}$

The only histologically negative patients who were seropositive by ELISA and immunoblotting but in whom no $H$ pylori were seen had the histological changes characteristic of "chemical gastritis" in their antral biopsy specimens. The strongly positive results by immunoblotting confirm that these three patients had a true systemic response against the bacterium. The discrepancy might be explained either by a patchy infection, or, alternatively, the histology of "chemical gastritis" may perhaps be mimicked by the healing stage of $H$ pylori gastritis. Exclusion of these patients from data analysis would improve the assay specificity.

Although seropositivity for $H$ pylori increases with age, ${ }^{7}$ the association between seropositivity and colonisation in the elderly seems to be less clear. Increasing hypochlorhydria with age can be associated with bacterial overgrowth. ${ }^{22}$ Reduced immunological responses in the elderly are well documented. ${ }^{23}$ Consideration of age profiles is therefore important when assessing $H$ pylori ELISA sensitivity and specificity. Our own data show improved sensitivity and specificity of the commercial $H$ pylori ELISA for patients under 61 years old. Some studies evaluating the sensitivity and specificity of $H$ pylori IgG ELISAs, however, give no age details of patients included.$^{810}$ As one major role for $H$ pylori serology is likely to be screening younger dyspeptic patients to eliminate unnecessary endoscopies, ${ }^{24}$ evalua- tion of the assay efficacy in younger patients is more clinically relevant.

$H$ pylori serology represents a rapid, noninvasive test for determining colonisation of $H$ pylori. The availability of a commercial ELISA with high sensitivity and specificity for $H$ pylori makes it applicable now for use in routine diagnostic laboratories. This study was undertaken with financial support from the Yorkshire Regional Health Authority and Gist-brocades. We immunoblotting investigations.

1 Rathbone BJ, Wyatt JI, Worsley BW, et al. Systemic and ocal antibody responses to gastric Campylobacter pyloridis in non-ulcer dyspepsia. Gut 1986;27:642-7.

2 Booth L, Holdstock G, MacBride H, et al. Clinical importance of Campylobacter pyloridis and associated serum IgG and IgA antibody responses in patients undergoing upper gastrointestinal endoscopy. J Clin Pathol 1986;39: 215-9.

3 Goodwin CS, Blincow E, Paterson G, et al. Enzyme-linked immunosorbent assay for Campylobacter pyloridis: correlation with presence of $\mathrm{C}$ pyloridis in the gastric mucosa. J Infect Dis 1987;155:488-94.

4 Rathbone BJ, Heatley RV. Immunology of Campylobacter pylori infections. In: Blaser MJ, ed. Campylobacter pylori in gastritis and peptic ulcer disease. Tokyo: Igaku-Shoin 1989:135-45.

5 Steer HW, Hawtin PR, Newell DG. An ELISA technique for the serodiagnosis of Campylobacter pyloridis infection in patients with gastritis and benign duodenal ulceration. Serodiag Immunother 1987;1:253-9.

6 Jones DM, Lessells AM, Eldridge J. Campylobacter-like organisms on the gastric mucosa: culture, histological, and serological studies. J Clin Pathol 1984;37:1002-6.

7 Jones DM, Eldridge J, Fox AJ, et al. Antibody to the gastric Campylobacter-like organism (Campylobacter pyloridis)-clinical correlations and distribution in the normal population. J Med Microbiol 1986;22:57-62.

8 Bolton FJ, Hutchinson DN. Evaluation of three Campylobacter pylori antigen preparations for screening sera from patients undergoing endoscopy. J Clin Pathol

9 Loffeld RJLF, Stobberingh E, Flendrig JA, Spreeuwel JP van, Arends JW. Diagnostic value of an immunoassay to detect anti Campylobacter pylori antibodies in non-ulcer dyspepsia. Lancet 1989;i:1182-5.

10 Perez-Perez GI, Dworkin BM, Chodos JE, Blaser MJ. Campylobacter pylori antibodies in humans. Ann Int Med 1988;109:11-7.

11 Evans DJ, Evans DG, Graham DY, Klein PD. A sensitive and specific serologic test for detection of Campylobacter pylori infection. Gastroenterology 1989;96:1004-8.

12 Rathbone BJ, Wyatt JI, Heatley RV Campylobacter pyloridis: a new factor in peptic ulcer disease. Gut 1986; 27:635-41.

13 Whitehead R, Truelove SC, Gear MWL. The histological diagnosis of chronic gastritis in fibreoptic gastroscope biopsy specimens. J Clin Pathol 1972;25:1-11.

14 Wyatt JI, Dixon MS. Chronic gastritis-a pathogenetic approach. J Pathol 1988;154:113-24.

15 Gray SF, Wyatt JI, Rathbone BJ. Simplified techniques for identifying gastric Campylobacter pylori on tissue sections. J Clin Pathol 1986;39:1279-80.

16 Morris A, Ali MR, Brown P, Lane M, Patton K. Campylobacter pylori infection in biopsy specimens of gastric antrum; laboratory diagnosis and estimation of sampling error. J Clin Pathol 1989;42:727-32.

17 Blake MS, Johnstone KH, Russell-Jones GJ, Gotschlich EC. A rapid, sensitive method for detection of alkaline phosphatase-conjugated anti-antibody on Western blots. phosphatase-conjugated anti-an

18 Barthel JS, Everett ED. Diagnosis of Campylobacter pylori infections: the "gold standard" and the alternatives. Rev Infect Dis 1990;12:S107-14.

19 Sobala GM, Crabtree JE, Dixon MF, et al. Acute Helicobacter pylori infection: clinical features, local and systemic immune response, gastric mucosal histology and gastric juice ascorbic acid concentrations. Gut 1991 (in press).

20 Dent JC, McNulty CAM, Uff JS, Gear MWL, Wilkinson SP. Campylobacter pylori urease: a new serological test. Lancet 1988;i:1002.

21 Hirschl AM, Rathbone BJ, Wyatt JI, Berger J, Rotter ML. Comparison of ELISA antigen preparations alone or in combination for serodiagnosing Helicobacter pylori infections. J Clin Pathol 1990;43:511-3.

22 Dooley CP, Cohen H, FitzGibbons PL, et al. Prevalence of Helicobacter pylori infection and histologic gastritis in asymptomatic persons.

23 Horan MA unifying hypothesis? Mechanisms of Ageing and Develop-
ment 1984;26:165-81.

24 Sobala GM, Rathbone BJ, Wyatt JI, Dixon MF, Heatley RV, Axon ATR. Investigating young patients with dysRV, Axon ATR. Investigating
pepsia. Lancet $1989 ; \mathrm{i}: 50-1$. 